\title{
Dental Percussion
}

National Cancer Institute

\section{Source}

National Cancer Institute. Dental Percussion. NCI Thesaurus. Code C62298.

A diagnostic test performed on a tooth by tapping on the crown with a dental instrument. 